\title{
Does the Plant Matrix Type Have Impact on Rutin Transformation During Its Extraction?
}

\author{
Andrzej L. Dawidowicz ${ }^{1}$ - Katarzyna Bernacik ${ }^{1} \cdot$ Rafal Typek $^{1}$
}

Received: 1 September 2015 / Accepted: 18 December 2015 /Published online: 5 January 2016

(C) The Author(s) 2016. This article is published with open access at Springerlink.com

\begin{abstract}
Rutin is a flavonoid glycoside found in many plants. It is used as medication and an ingredient of numerous multivitamin preparations and herbal remedies due to its biomedical activity. The present paper deals with transformation processes of rutin during its extraction by methanol, ethanol, and their aqueous mixtures from Aronia melanocarpa (M.) E. and Sambucus nigra L. fruits, Hypericum perforatum L. herb, and Tussilago farfara L. leaves, known as ones of the most riches in rutin plant materials. It has been established that the transformation degree of rutin during its extraction depends not only on extraction time and extractant type but also, to a high degree, on the plant matrix type. Differences in the degree of rutin transformation are influenced by the matrix components in the examined plants. The reported results are particularly important for researchers investigating plant metabolism and looking for new plant components.
\end{abstract}

Keywords Rutin · Rutoside $\cdot$ Rutin transformation · Rutin degradation $\cdot$ Rutin stability $\cdot$ Extraction

\section{Introduction}

More and more attention has been paid recently to the role and application of secondary plant metabolites which, due to their

Electronic supplementary material The online version of this article (doi:10.1007/s12161-015-0388-z) contains supplementary material, which is available to authorized users.

Andrzej L. Dawidowicz

dawid@poczta.umcs.lublin.pl

1 Faculty of Chemistry, Maria Curie Sklodowska University, Pl. Maria Curie Sklodowska 3, 20-031 Lublin, Poland biochemical properties, are often applied by physicians, pharmacists, dieticians, etc. (Bourgaud et al. 2001; Crozier et al. 2006; Kennedy and Wightman 2011; Pandey and Rizvi 2009). Rutin, being a secondary plant metabolite, is one of the highly valued compounds. Its antifungal, antibacterial, antiinflammatory and anticancer properties and the ability of radical scavenging are most frequently discussed (Biesaga 2011; Guardia et al. 2001; Mohd Zainol et al. 2009; Navarro-Núñez et al. 2008; Wang et al. 2011; Yang et al. 2008; You et al. 2010). These properties require better knowledge of rutin itself, its transformations, and its occurrence and metabolism in plants. An inquiry into the analytical procedures involving rutin is an important step in this cognition process. The analysis of plant constituents requires the application of sample preparation methods allowing for full isolation of the analyzed substances from the plant matrix (Dawidowicz and Wianowska 2009). The most procedures of rutin determination in plants involve their high-temperature extraction prior to HPLC analysis and the application of methanol and methanol-water mixtures as extractants (Andrade et al. 1997; Dawidowicz et al. 2003; Suárez-Quiroz et al. 2014; Uppugundla et al. 2009; Wianowska et al. 2015).

In our previous studies (Dawidowicz et al. 2016), we found that as many as 23 derivative compounds and reaction products with methanol were formed from rutin during its extraction by methanol or methanol/water solution. These compounds can be mistakenly treated as new compounds not found before in the examined plant or can be a cause of erroneous quantitative estimations of plant composition. We concluded that more detailed experiments with rutin extraction from flowers of Sambucus nigra L. were needed to determine the possible influence of the plant matrix type on rutin transformation and degradation processes. To see if this is indeed the case, we examined in this 
study the transformation process of rutin during its extraction from Aronia melanocarpa (M.) E. and S. nigra L. fruits, Hypericum perforatum L. herb, and Tussilago farfara L. leaves, rutin-rich plant materials. As the rutin concentration level in the examined plant materials is different, all extractions were performed with a similar rutin amount in the extraction systems to maintain a similar quantitative ratio between rutin and extractant. Consequently, the amounts of the selected plant materials in the extraction processes had to be different. Methanol, ethanol, and their mixtures with water were applied as extractants in all the experiments.

\section{Materials and Methods}

\section{Materials and Reagents}

The A. melanocarpa fruits (M.) E., S. nigra L. fruits, $H$. perforatum L. herb, and T. farfara $\mathrm{L}$. leaves, cultivated in the eastern part of Poland, were air-dried at $+35^{\circ} \mathrm{C}$ and stored at $+4{ }^{\circ} \mathrm{C}$. Acetonitrile (HPLC), methanol, and ethanol were purchased from the Polish Chemical Plant POCh (Gliwice, Poland) and formic acid from Sigma-Aldrich (Seelze, Germany). Water was purified on the Milli-Q system from Millipore (Millipore, Bedford, MA, USA).

\section{Investigations of Rutin Transformation Process During Rutin Extraction from Plant Materials}

Investigations of the rutin transformation process were performed by heating plant material suspensions in methanol or ethanol or alcohol/water $(75 / 25 \mathrm{v} / \mathrm{v})$ mixtures. The glass equipment consisted of a boiling flask $(100 \mathrm{~mL})$ and a small condenser. The heated plant suspensions were composed of $50 \mathrm{~mL}$ of a given extractant and an amount of plant material containing about $10 \mathrm{mg}$ of rutin. Rough rutin concentration in the examined plants was established prior to the experiments following the procedure described below. Individual plant suspensions were heated for 1 or 2 or $3 \mathrm{~h}$. The extracts were centrifuged, and the obtained supernatants were subjected to liquid chromatography-mass spectrometry-diode array detector (LC-MS-PDA) analysis.

\section{Estimation of Rutin Concentration in Examined Plant Materials}

The exactly weighed portions $(0.3 \mathrm{~g})$ of grounded plant materials were ultrasonicated with $50 \mathrm{~mL}$ of methanol/water $(75 / 25$ $v / v)$ mixture for $1 \mathrm{~h}$ at $40^{\circ} \mathrm{C}$. Subsequently, the supernatants isolated by centrifuging were subjected to LC-MS-PDA analysis.

\section{HPLC Measurements}

The chromatographic measurements were performed using LC/MS from Finnigan (LCQ Advantage Max) equipped with the ion-trap mass spectrometric system (Thermo Electron Corporation, San Jose, CA) and diode array detector from Finnigan (Surveyor PDA Plus Detector). The Gemini C18 column $(4.6 \times 100 \mathrm{~mm}$, $3 \mu \mathrm{m}$ ) (Phenomenex, USA) was employed for chromatographic separation, which was performed using gradient elution and flow rate of $0.4 \mathrm{~mL} / \mathrm{min}$. The mobile phase A was $25 \mathrm{mM}$ formic acid in water; the mobile phase B was $25 \mathrm{mM}$ formic acid in acetonitrile. The gradient program started at $5 \% \mathrm{~B}$ increasing to $35 \%$ for $60 \mathrm{~min}$, next $35 \% \mathrm{~B}$ to $95 \% \mathrm{~B}$ for $12 \mathrm{~min}$, and ended with isocratic elution followed (95\% B) for $3 \mathrm{~min}$. In the course of each run, PDA spectra in the range 190-600 $\mathrm{nm}$ and MS spectra in the range of $100-2000 \mathrm{~m} / \mathrm{z}$ were collected continuously. In all rutin solutions and $S$. nigra L. fruits, the selected ion monitoring (SIM) function was used to better visualize the chromatographic separation and to remove the signal connected with rutin, plant matrix, and buffer components. The time periods and monitored ions were as follows:

0-15.5 min $(197 \mathrm{~m} / \mathrm{z}), 15.5-16 \mathrm{~min}(211 \mathrm{~m} / \mathrm{z}), 16-17 \mathrm{~min}$ $(179 \mathrm{~m} / \mathrm{z}), 17-17.5 \mathrm{~min}(225 \mathrm{~m} / \mathrm{z}), 17.5-18 \mathrm{~min}(305 \mathrm{~m} / \mathrm{z})$, $18-19 \mathrm{~min}(335 \mathrm{~m} / \mathrm{z}), 19-20 \mathrm{~min}(193 \mathrm{~m} / \mathrm{z}), 20-21 \mathrm{~min}$ $(319 \mathrm{~m} / \mathrm{z})$,

21-23 $\mathrm{min}(317 \mathrm{~m} / \mathrm{z}), 23-25 \mathrm{~min}(207 \mathrm{~m} / \mathrm{z}), 25-27 \mathrm{~min}$ $(331 \mathrm{~m} / \mathrm{z}), 27-29 \mathrm{~min}(257 \mathrm{~m} / \mathrm{z})$,

29-31 $\mathrm{min}(345 \mathrm{~m} / \mathrm{z}), 31-34 \mathrm{~min}(271 \mathrm{~m} / \mathrm{z}), 34-34.5 \mathrm{~min}$ $(349 \mathrm{~m} / \mathrm{z}), 34.5-35 \mathrm{~min}(333 \mathrm{~m} / \mathrm{z})$,

35-40 $\mathrm{min}(363 \mathrm{~m} / \mathrm{z}), 40-42 \mathrm{~min}(463 \mathrm{~m} / \mathrm{z}), 42-45 \mathrm{~min}$ $(623 \mathrm{~m} / \mathrm{z}), 45-46 \mathrm{~min}(347 \mathrm{~m} / \mathrm{z})$,

46-47 $\mathrm{min}(447 \mathrm{~m} / \mathrm{z}), 47-48 \mathrm{~min}(637 \mathrm{~m} / \mathrm{z}), 48-49 \mathrm{~min}$ $(477 \mathrm{~m} / \mathrm{z}), 49-51 \mathrm{~min}(491 \mathrm{~m} / \mathrm{z})$,

51-56 $\mathrm{min}(461 \mathrm{~m} / \mathrm{z}), 56-59 \mathrm{~min}(475 \mathrm{~m} / \mathrm{z}), 59-63 \mathrm{~min}$ $(301 \mathrm{~m} / \mathrm{z}), 63-65 \mathrm{~min}(273 \mathrm{~m} / \mathrm{z})$,

65-67 $\mathrm{min}(361 \mathrm{~m} / \mathrm{z}), 67-71 \mathrm{~min}(315 \mathrm{~m} / \mathrm{z}), 71-75 \mathrm{~min}$ $(329 \mathrm{~m} / \mathrm{z})$.

The column effluent was ionized by electrospray ionization (ESI). The ESI was operated in negative polarity mode under the following specific conditions: spray voltage $-4.5 \mathrm{kV}$, sheath gas -40 arbitrary units, auxiliary gas -10 arbitrary units, sweep gas -10 arbitrary units, and capillary temperature $-320^{\circ} \mathrm{C}$. Nitrogen $(>99.98 \%)$ was employed as sheath, auxiliary, and sweep gas. All eluate was subjected to ionization. The collision energy was chosen individually for the examined compounds. 
To identify rutin derivatives (the products of its hydrolysis, transformation, and oxidation), the function of secondary $\left(\mathrm{MS}^{2}\right)$ ion fragmentation was applied. The collision energy for each examined compound was chosen individually. For confirmation, high-resolution mass spectrometry (HRMS) analysis was additionally performed.

The HRMS analysis was carried out on the HPLC system coupled to a linear trap quadrupole-Orbitrap mass spectrometer (LTQ-Orbitrap Velos from Thermo Fisher Scientific, San Jose, CA) equipped with an ESI source. The ESI was operated in negative polarity modes under the following specific conditions: spray voltage $-3.5 \mathrm{kV}$, sheath gas -40 arbitrary units, auxiliary gas -10 arbitrary units, sweep gas -10 arbitrary units, and capillary temperature $-320{ }^{\circ} \mathrm{C}$. Nitrogen (>99.98\%) was employed as sheath, auxiliary, and sweep gas. The scan cycle used a full-scan event at the resolution of 60,000 . All eluate was subjected to ionization. The collision energy was chosen individually for the examined compounds.

Due to the lack of standards of rutin derivatives, their amounts were estimated by relating their chromatographic responses to the calibration curve for rutin and its aglycone, quercetin.

The calibration curve for rutin was used for estimating the amounts of the following glycoside rutin derivatives:

- 2-(3,4-Dihydroxyphenyl)-5,7-dihydroxy-3-[(2S,3R,4S, 5S,6R)-3,4,5-trihydroxy-6-(hydroxymethyl)oxan-2yl]oxychromen-4-one (isoquercitrin);

- 2-(3,4-Dihydroxyphenyl)-7-hydroxy-5-methoxy-3-[(2S, 3R,4S,5S,6R)-3,4,5-trihydroxy-6-(hydroxymethyl)oxan2-yl]oxychromen-4-one (methyl-isoquercitrin);

- 2-(3,4-Dihydroxyphenyl)-5-ethoxy-7-hydroxy-3-[(2S, 3R,4S,5S,6R)-3,4,5-trihydroxy-6-(hydroxymethyl)oxan2-yl]oxychromen-4-one (ethyl-isoquercitrin);

- 2-(3,4-Dihydroxyphenyl)-5,7-dihydroxy-3-[(2S,3R, 4R, 5R, 6S)-3,4,5-trihydroxy-6-methyloxan-2yl]oxychromen-4-one (quercitrin);

- 2-(3,4-Dihydroxyphenyl)-7-hydroxy-5-methoxy-3-[(2S, 3R,4R,5R,6S)-3,4,5-trihydroxy-6-methyloxan-2yl]oxychromen-4-one (methyl-quercitrin);

- 2-(3,4-Dihydroxyphenyl)-5-ethoxy-7-hydroxy-3-[(2S, 3R,4R, 5R,6S)-3,4,5-trihydroxy-6-methyloxan-2yl]oxychromen-4-one (ethyl-quercitrin);

- 2-(3,4-Dihydroxyphenyl)-7-hydroxy-5-methoxy-3-[(2S, 3R,4S,5S,6R)-3,4,5-trihydroxy-6-[[(2R,3R,4R,5R,6S)-3, 4,5-trihydroxy-6-methyloxan-2-yl]oxymethyl]oxan-2yl]oxychromen-4-one (methyl-rutin);

- 2-(3,4-Dihydroxyphenyl)-5-ethoxy-7-hydroxy-3-[(2S, 3R,4S,5S,6R)-3,4,5-trihydroxy-6-[[(2R,3R,4R,5R,6S)-3, 4,5-trihydroxy-6-methyloxan-2-yl]oxymethyl]oxan-2yl]oxychromen-4-one (ethyl-rutin);
The calibration curve for quercetin was applied for estimating the amounts of the following aglicon rutin derivatives:

- 2-[(3,4-Dihydroxyphenyl)carbonyl]-2,4,6-trihydroxy-1benzofuran-3(2H)-one (DTB);

- 2-[(3,4-Dihydroxyphenyl)carbonyl]-4,6-dihydroxy-2methoxy-1-benzofuran-3(2H)-one (methyl-DTB);

- 2-[(3,4-Dihydroxyphenyl)carbonyl]-2-ethoxy-4,6-dihydroxy-1-benzofuran-3(2H)-one (ethyl-DTB);

- Oxo(2,4,6-trihydroxyphenyl)acetic acid (OTA);

- Methyl oxo(2,4,6-trihydroxyphenyl)acetate (methylOTA);

- Ethyl oxo(2,4,6-trihydroxyphenyl)acetate (ethyl-OTA);

- 2-[Carboxy(3,4-dihydroxyphenyl)methoxy]-4,6dihydroxybenzoic acid (CDA);

- 2-[1-(3,4-Dihydroxyphenyl)-2-methoxy-2-oxoethoxy]-4, 6-dihydroxybenzoic acid (methyl-CDA);

- 2-[1-(3,4-Dihydroxyphenyl)-2-ethoxy-2-oxoethoxy]-4, 6-dihydroxybenzoic acid (ethyl-CDA);

- 2-\{[(3,4-Dihydroxyphenyl)carbonyl $]$ oxy $\}-4,6$ dihydroxybenzoic acid (DDA);

- Methyl 2-\{[(3,4-dihydroxyphenyl)carbonyl $]$ oxy $\}-4,6-$ dihydroxybenzoate (methyl-DDA);

- Ethyl 2-\{[(3,4-dihydroxyphenyl)carbonyl]oxy\}-4,6dihydroxybenzoate (ethyl-DDA);

- 4,6-Dihydroxy-1-benzofuran-2,3-dione (DBD);

- 6-Hydroxy-4-methoxy-1-benzofuran-2,3-dione (methylDBD);

- 4-Ethoxy-6-hydroxy-1-benzofuran-2,3-dione (ethylDBD);

- 7-(3,4-Dihydroxyphenyl)bicyclo[4.2.0]octa-1,3,5,7tetraene-2,4,8-triol (DBOT);

- 7-(3,4-Dihydroxyphenyl)-8-methoxybicyclo[4.2.0]octa1,3,5,7-tetraene-2,4-diol (methyl-DBOT);

- 3,5-Dihydroxy-2-[methoxy(oxo)acetyl]phenyl 3,4dihydroxybenzoate (DPD);

- 5-Hydroxy-3-methoxy-2-[methoxy(oxo)acetyl]phenyl 3, 4-dihydroxybenzoate (methyl-DPD);

- 2-(3,4-Dihydroxyphenyl)-3,5,7-trihydroxychromen-4one (quercetin);

- 2-(3,4-Dihydroxyphenyl)-5,7-dihydroxy-3methoxychromen-4-one (methyl-quercetin);

- 2-(3,4-Dihydroxypheny 1)-3-ethoxy-5, 7dihydroxychromen-4-one (ethyl-quercetin);

- 2-(3,4-Dihydroxyphenyl)-1-benzofuran-3,4,6-triol (DBT).

\section{Statistical Analysis}

All the results are presented as the mean of three independent measurements $(n=3)$. Differences in the concentration of the formed rutin derivatives were compared using the 
analysis of variance (ANOVA, $p=0.05$ ). Differences in the studied group were considered significant for $p$ value lower than 0.05 and $F$ value higher than 4.26. The ANOVA revealed statistically significant differences only for a few tested groups.

\section{Results and Discussion}

Figure 1 presents the exemplary chromatograms of methanolic (Fig. 1a), methanol/water (Fig. 1b), ethanolic (Fig. 1c), and ethanol/water (Fig. 1d) supernatants after 3-h extraction of H. perforatum $\mathrm{L}$. herb under reflux. Figure $1 \mathrm{a}, \mathrm{b}$ illustrates the presence of almost all rutin derivatives (formed during the heating of methanolic or methanol/water rutin solution; Dawidowicz et al. 2016) in the methanolic or methanol/ water extract of the herb. Yet, it is uncertain which of them are native components of $H$. perforatum $\mathrm{L}$. The chromatographic analysis (Fig. 1c) shows that 17 rutin transformation products and their ethyl derivatives are present in $H$. perforatum L. ethanolic extract. The absence of methyl derivatives of rutin and its transformation products in ethanolic extracts and, vice versa, the absence of ethyl derivatives of rutin and its transformation products in methanolic extracts of $H$. perforatum L. prove that alcoholic rutin derivatives are non-native $H$. perforatum L. components formed during the rutin extraction process from the plant. The same conclusion is valid for the fruits of A. melanocarpa (M.) E. and $S$. nigra L. and the leaves of T. farfara L. The exemplary chromatograms of their methanolic, methanol/water, ethanolic, and ethanol/water extracts are shown in Figs. S1a-f and Fig. S2a-f, respectively (Supplementary Material). The structures of all rutin derivatives found in the examined extracts are shown in Fig. 2. All of them were identified and confirmed on the basis of the retention data of their standards, the PDA, MS ${ }^{2}$, HRMS, and literature data (Dubber et al. 2005; Wang et al. 2011; Zenkevich et al. 2007; Zvezdanović et al. 2012). The MS $^{2}$ and HRMS data for the identified compounds are collected in Tables 1 and 2, respectively. $\mathrm{MS}^{1}$ and $\mathrm{MS}^{2}$ spectra for one exemplary rutin derivative, OTA, are presented in Fig. S3 (Supplementary Material).

While the alcoholic rutin derivatives are evidently non-native components of the examined plants, it is more difficult to determine unequivocally to the origin of the non-alcoholic rutin derivatives. There is no doubt about quercetin, isoquercitrin, and quercitrin which are truly native plant components involved in the rutin metabolic pathway, but the origin of DTB, OTA, CDA, DDA, DPD, DBT, DBD, and DBOT is less certain. As shown in Dawidowicz et al. (2016), they are formed during the heating of methanolic and methanol/water rutin solution, and they are also known as rutin and/or quercetin degradation products forming during their high-temperature treatment, UV irradiation, or exposure to other aggressive factors (Dubber et al. 2005; Rohn et al. 2007; Wang et al. 2011; Zenkevich et al. 2007; Zvezdanović et al. 2012). The presented data show that some of them are formed during the heating of ethanolic and ethanol/water rutin solution.
Fig. 1 Exemplary chromatograms of methanolic (a), methanol/water 75/25 v/v (b), ethanolic (c), and ethanol/water $75 / 25 v / v$ (d) supernatants of Hypericum perforatum $\mathrm{L}$. herb after 3-h extraction under reflux. Peak numbers correspond to compound numbers reported in Fig. 2

HO

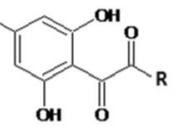

$1 \mathrm{R}=\mathrm{OH}$

1' $\mathrm{R}=\mathrm{OCH}_{3}$

1" $\mathrm{R}=\mathrm{OCH}_{2} \mathrm{CH}_{3}$
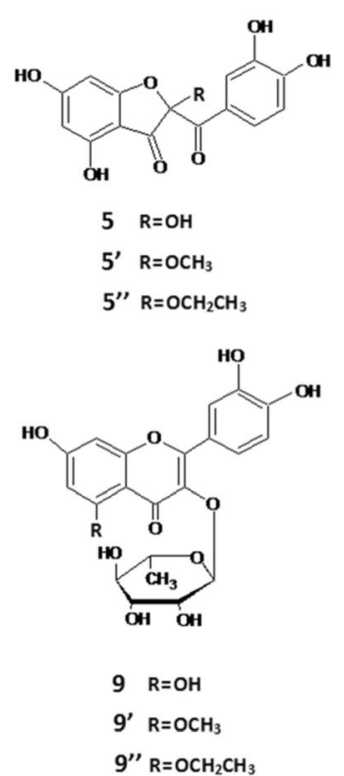

9" $\mathrm{R}=\mathrm{OCH}_{2} \mathrm{CH}_{3}$

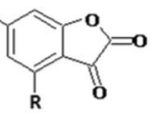

$2 \mathrm{R}=\mathrm{OH}$

2' $\mathrm{R}=\mathrm{OCH}_{3}$

2" $\mathrm{R}=\mathrm{OCH}_{2} \mathrm{CH}_{3}$

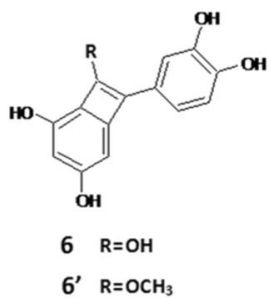

6' $\mathrm{R}=\mathrm{OCH}_{3}$<smiles>[R]c1c(-c2ccc(O)c(O)c2)oc2cc(O)cc(O)c2c1=O</smiles>

$10 \mathrm{R}=\mathrm{OH}$

10' $\mathrm{R}=\mathrm{OCH}_{3}$

10 " $\mathrm{R}=\mathrm{OCH}_{2} \mathrm{CH}_{3}$
Fig. 2 Molecular structures of rutin and its transformation products: (1) oxo(2,4,6-trihydroxyphenyl)acetic acid; (1') methyl oxo(2,4,6trihydroxyphenyl)acetate; (1") ethyl oxo(2,4,6trihydroxyphenyl)acetate; (2) 4,6-dihydroxy-1-benzofuran-2,3-dione; (2') 6-hydroxy-4-methoxy-1-benzofuran-2,3-dione; (2") 4-ethoxy-6hydroxy-1 - benzofuran-2,3-dione; (3) 2 - \{ [ (3, 4 dihydroxyphenyl)carbonyl]oxy\}-4,6-dihydroxybenzoic acid; (3') methyl $2-\{[(3,4$-dihydroxyphenyl)carbonyl $]$ oxy $\}-4,6-$ dihydroxybenzoate ; (3") e thy $12-\{[(3,4-$ dihydroxyphenyl)carbonyl]oxy $\}$-4,6-dihydroxybenzoate; (4) 2[carboxy(3,4-dihydroxyphenyl)methoxy]-4,6-dihydroxybenzoic acid; (4') 2-[1-(3,4-dihydroxyphenyl)-2-methoxy-2-oxoethoxy]-4,6dihydroxybenzoic acid; (4") 2-[1-(3,4-dihydroxyphenyl)-2-ethoxy-2oxoethoxy]-4,6-dihydroxybenzoic acid; (5) $2-[(3,4-$ dihydroxyphenyl)carbonyl]-2,4,6-trihydroxy-1-benzofuran-3(2H)-one; (5') 2-[(3,4-dihydroxyphenyl)carbonyl]-4,6-dihydroxy-2-methoxy-1benzofuran-3(2H)-one; (5") 2-[(3,4-dihydroxyphenyl)carbonyl]-2ethoxy-4,6-dihydroxy-1-benzofuran-3(2H)-one; (6) 7-(3,4dihydroxyphenyl)bicyclo[4.2.0]octa-1,3,5,7-tetraene-2,4,8-triol; (6') 7(3,4-dihydroxyphenyl)-8-methoxybicyclo[4.2.0]octa-1,3,5,7-tetraene2,4-diol; (7) 2-(3,4-dihydroxyphenyl)-5,7-dihydroxy-3[(2S,3R,4S, 5S,6R)-3,4,5-trihydroxy-6-(hydroxymethyl)oxan-2yl]oxychromen-4-one; (7') 2-(3,4-dihydroxyphenyl)-7-hydroxy-5meth oxy-3 - [ (2 S , 3 R, 4 S , 5 S, 6R ) - 3, 4, 5 - trihydroxy-6-

As methanol-water mixtures containing $70-80 \%$ of the alcohol are the most frequently applied extrahents for the isolation of flavonoids from plant materials<smiles>[R]C(=O)c1c(O)cc(O)cc1OC(=O)c1ccc(O)c(O)c1</smiles>

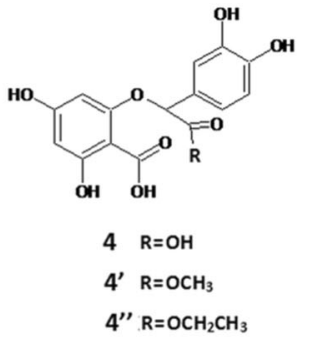

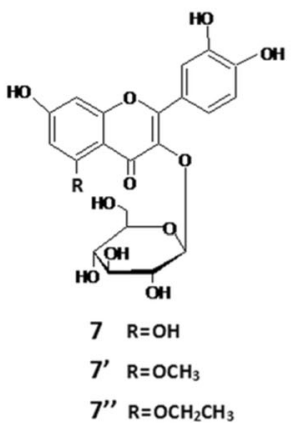<smiles>[R]c1cc(O)cc(OC(=O)c2ccc(C)c(O)c2)c1C(=O)C(=O)OC</smiles>



(hydroxymethyl)oxan-2-yl]oxychromen-4-one; (7") 2-(3,4dihydroxyphenyl)-5-ethoxy-7-hydroxy-3-[(2S,3R,4S,5S,6R)-3,4,5trihydroxy-6-(hydroxymethyl)oxan-2-yl] oxychromen-4-one; (8) 3,5dihydroxy-2-[methoxy(oxo)acetyl]phenyl 3,4-dihydroxybenzoate; (8') 5-hydroxy-3-methoxy-2-[methoxy(oxo)acetyl]phenyl 3,4dihydroxybenzoate; (9) 2-(3,4-dihydroxyphenyl)-5,7-dihydroxy-3[(2S,3R,4R,5R,6S)-3,4,5-trihydroxy-6-methyloxan-2-yl]oxychromen-4one; (9') 2-(3,4-dihydroxyphenyl)-7-hydroxy-5-methoxy-3[(2S,3R,4R,5R,6S)-3,4,5-trihydroxy-6-methyloxan-2-yl]oxychromen-4one; (9") 2-(3,4-dihydroxyphenyl)-5-ethoxy-7-hydroxy-3[(2S,3R,4R,5R,6S)-3,4,5-trihydroxy-6-methyloxan-2-yl] oxychromen-4one; (10) 2-(3,4-dihydroxyphenyl)-3,5,7-trihydroxychromen-4-one; (10') 2-(3,4-dihydroxyphenyl)-5,7-dihydroxy-3-methoxychromen-4one; (10") 2-(3,4-dihydroxyphenyl)-3-ethoxy-5,7-dihydroxychromen-4one; (11) 2-(3,4-dihydroxyphenyl)-1-benzofuran-3,4,6-triol; (12) 2-(3,4dihydroxyphenyl)-5,7-dihydroxy-3-[(2S,3R,4S,5S,6R)-3,4,5-trihydroxy6-[[(2R,3R,4R, 5R, 6S )-3,4,5-trihydroxy-6-methyloxan-2yl]oxymethyl]oxan-2-yl]oxychromen-4-one; (12') 2-(3,4dihydroxyphenyl)-7-hydroxy-5-methoxy-3-[(2S,3R,4S,5S,6R)-3,4,5trihydroxy-6-[[(2R,3R,4R,5R,6S)-3,4,5-trihydroxy-6-methyloxan-2yl]oxymethyl]oxan-2-yl] oxychromen-4-one; (12") 2-(3,4dihydroxyphenyl)-5-ethoxy-7-hydroxy-3-[(2S,3R,4S,5S,6R)-3,4,5trihydroxy-6-[[(2R,3R,4R,5R,6S)-3,4,5-trihydroxy-6-methyloxan-2yl]oxymethyl]oxan-2-yl]oxychromen-4-one

(Andrade et al. 1997; Dawidowicz et al. 2003; SuárezQuiroz et al. 2014; Uppugundla et al. 2009; Wianowska et al. 2015), the examination of the influence of 
Table 2 The HRMS data for rutin transformation products

\begin{tabular}{|c|c|c|c|c|c|}
\hline Compound & $\begin{array}{l}\text { Elemental } \\
\text { composition }[\mathrm{M}-\mathrm{H}]^{-}\end{array}$ & $\begin{array}{l}\text { Theoretical } \\
\text { mass }[\mathrm{M}-\mathrm{H}]-(\mathrm{Da})\end{array}$ & $\begin{array}{l}\text { Experimental } \\
\text { mass }[\mathrm{M}-\mathrm{H}]^{-}(\mathrm{Da})\end{array}$ & $\Delta \mathrm{mDa}$ & $\Delta \mathrm{ppm}$ \\
\hline OTA & $\mathrm{C}_{8} \mathrm{H}_{5} \mathrm{O}_{6}$ & 197.00862 & 197.00822 & -0.40 & 2.03 \\
\hline Methyl-OTA & $\mathrm{C}_{9} \mathrm{H}_{7} \mathrm{O}_{6}$ & 211.02427 & 211.02347 & -0.80 & 3.79 \\
\hline Ethyl-OTA & $\mathrm{C}_{10} \mathrm{H}_{9} \mathrm{O}_{6}$ & 225.03992 & 225.03921 & -0.71 & 3.15 \\
\hline DBD & $\mathrm{C}_{8} \mathrm{H}_{3} \mathrm{O}_{5}$ & 178.99805 & 178.99884 & 0.79 & 4.41 \\
\hline Methyl-DBD & $\mathrm{C}_{9} \mathrm{H}_{5} \mathrm{O}_{5}$ & 193.01370 & 193.01238 & -1.32 & 6.84 \\
\hline Ethyl-DBD & $\mathrm{C}_{10} \mathrm{H}_{7} \mathrm{O}_{5}$ & 207.02935 & 207.02998 & 0.63 & -3.04 \\
\hline DDA & $\mathrm{C}_{14} \mathrm{H}_{9} \mathrm{O}_{8}$ & 305.02975 & 305.02898 & -0.77 & 2.52 \\
\hline Methyl-DDA & $\mathrm{C}_{15} \mathrm{H}_{11} \mathrm{O}_{8}$ & 319.04540 & 319.04496 & -0.44 & 1.38 \\
\hline Ethyl-DDA & $\mathrm{C}_{16} \mathrm{H}_{13} \mathrm{O}_{8}$ & 333.06105 & 333.06207 & 1.02 & -3.06 \\
\hline CDA & $\mathrm{C}_{15} \mathrm{H}_{11} \mathrm{O}_{9}$ & 335.04031 & 335.03893 & -1.38 & 4.12 \\
\hline Methyl-CDA & $\mathrm{C}_{16} \mathrm{H}_{13} \mathrm{O}_{9}$ & 349.05596 & 349.05584 & -0.12 & 0.34 \\
\hline Ethyl-CDA & $\mathrm{C}_{17} \mathrm{H}_{15} \mathrm{O}_{9}$ & 363.07161 & 363.07105 & -0.56 & 1.54 \\
\hline DTB & $\mathrm{C}_{15} \mathrm{H}_{9} \mathrm{O}_{8}$ & 317.02975 & 317.02910 & -0.65 & 2.05 \\
\hline Methyl-DTB & $\mathrm{C}_{16} \mathrm{H}_{11} \mathrm{O}_{8}$ & 331.04540 & 331.04588 & 0.48 & 1.45 \\
\hline Ethyl-DTB & $\mathrm{C}_{17} \mathrm{H}_{13} \mathrm{O}_{8}$ & 345.06105 & 345.06137 & 0.32 & -0.93 \\
\hline DBOT & $\mathrm{C}_{14} \mathrm{H}_{9} \mathrm{O}_{5}$ & 257.04500 & 257.04468 & -0.32 & 1.24 \\
\hline Methyl-DBOT & $\mathrm{C}_{15} \mathrm{H}_{11} \mathrm{O}_{5}$ & 271.06065 & 271.05956 & -1.09 & 4.02 \\
\hline Isoquercitrin & $\mathrm{C}_{21} \mathrm{H}_{19} \mathrm{O}_{12}$ & 463.08766 & 463.08705 & -0.61 & 1.32 \\
\hline Methyl-isoquercitrin & $\mathrm{C}_{22} \mathrm{H}_{21} \mathrm{O}_{12}$ & 477.10331 & 477.10298 & -0.33 & 0.69 \\
\hline Ethyl-isoquercitrin & $\mathrm{C}_{23} \mathrm{H}_{23} \mathrm{O}_{12}$ & 491.11896 & 491.11851 & -0.45 & 0.92 \\
\hline DPD & $\mathrm{C}_{16} \mathrm{H}_{11} \mathrm{O}_{9}$ & 347.04031 & 347.03932 & -0.99 & 2.85 \\
\hline Methyl-DPD & $\mathrm{C}_{17} \mathrm{H}_{13} \mathrm{O}_{9}$ & 361.05596 & 361.05514 & -0.82 & 2.27 \\
\hline Quercitrin & $\mathrm{C}_{21} \mathrm{H}_{19} \mathrm{O}_{11}$ & 447.09274 & 447.09499 & 2.25 & 5.03 \\
\hline Methyl-quercitrin & $\mathrm{C}_{22} \mathrm{H}_{21} \mathrm{O}_{11}$ & 461.10839 & 461.10910 & 0.71 & 1.54 \\
\hline Ethyl-quercitrin & $\mathrm{C}_{23} \mathrm{H}_{23} \mathrm{O}_{11}$ & 475.12404 & 475.12457 & 0.53 & -1.12 \\
\hline Quercetin & $\mathrm{C}_{15} \mathrm{H}_{9} \mathrm{O}_{7}$ & 301.03483 & 301.03525 & 0.42 & 1.40 \\
\hline Methyl-quercetin & $\mathrm{C}_{16} \mathrm{H}_{11} \mathrm{O}_{7}$ & 315.05048 & 315.04901 & -1.47 & 4.67 \\
\hline Ethyl-quercetin & $\mathrm{C}_{17} \mathrm{H}_{13} \mathrm{O}_{7}$ & 329.06613 & 329.06504 & -1.09 & 3.31 \\
\hline DBT & $\mathrm{C}_{14} \mathrm{H}_{9} \mathrm{O}_{6}$ & 273.03992 & 273.03866 & -1.26 & 4.61 \\
\hline Methyl-rutin & $\mathrm{C}_{28} \mathrm{H}_{31} \mathrm{O}_{16}$ & 623.16122 & 623.16211 & 0.89 & 1.43 \\
\hline Ethyl-rutin & $\mathrm{C}_{29} \mathrm{H}_{33} \mathrm{O}_{16}$ & 637.17687 & 637.17699 & 0.12 & -0.19 \\
\hline
\end{tabular}

non-native plant compounds by the increase of degradation degree of rutin and for native plant components (quercetin, quercitrin, isoquercitrin) by the increase of extraction efficiency. The observed initial increase of the amount of some rutin derivatives and the subsequent decrease can be treated as experimental error (see error bars). However, this behavior can also be the result of a simultaneous compound formation and degradation processes. The latter explanation is more probable since the trend is observed for the same substances irrespective of the applied plant matrix (Fig. 3). The formation of DPD and its degradation to OTA or the formation of methyl-quercetin and its degradation to methyl-CDA can be examples of such simultaneous processes.
In order, to determine the influence of the plant matrix type on the rutin transformation and degradation process, all extraction systems used in the experiments contained a similar amount of rutin but different amounts of individual plant materials. This rule ensured a similar initial quantitative ratio between rutin and extractant for all examined plants and made the comparison of the matrix type influence much easier. The analysis of the amounts of individual rutin derivatives formed during rutin extraction from the examined plant materials (see Fig. 3) proves that the plant matrix does not change of the shape of the observed dependences but influences significantly the intensity of the rutin transformation process. The greatest changes for non-methyl rutin derivatives are observed in the case of $T$. farfara L. leaves 

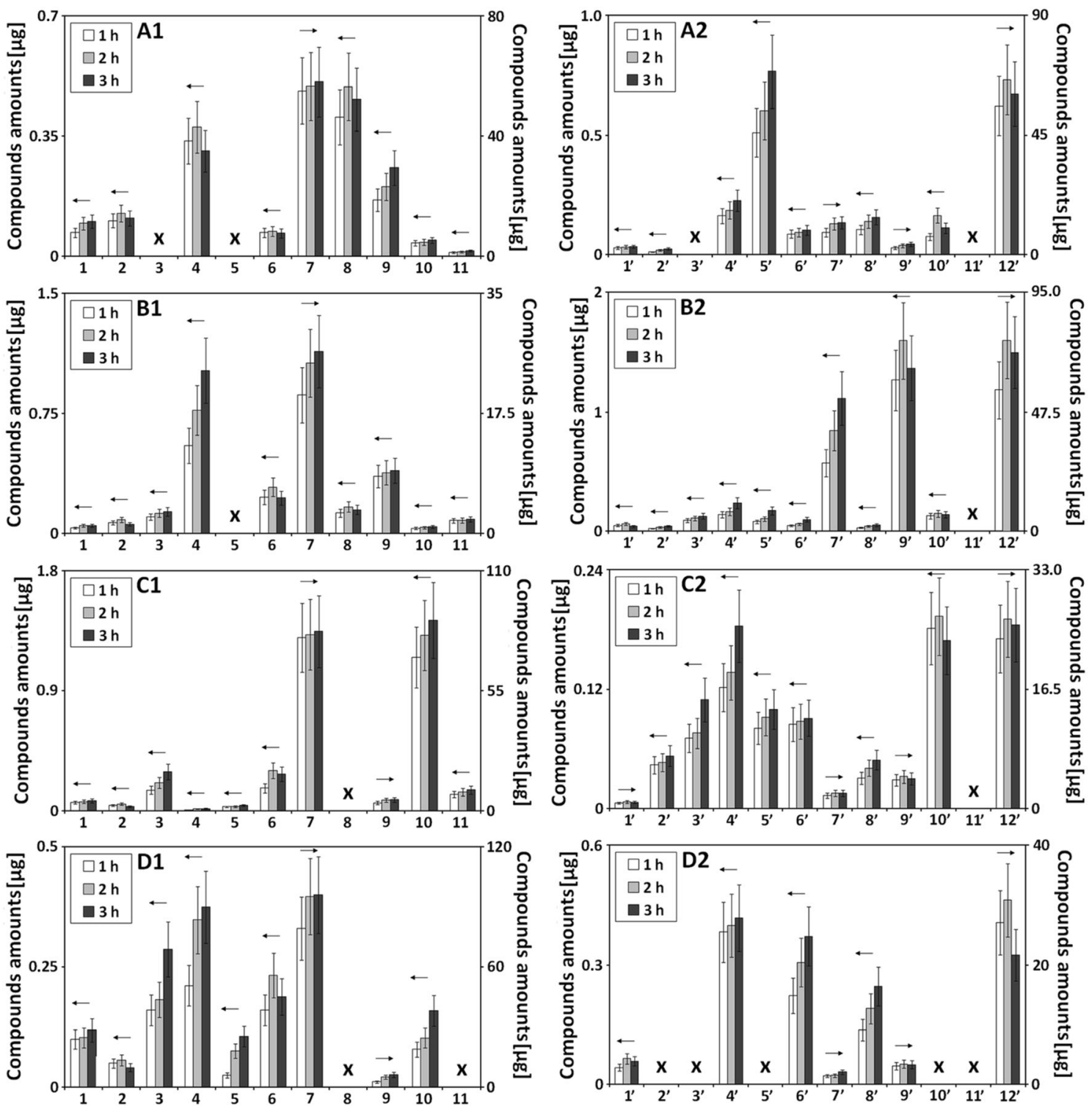

Fig. 3 The influence of plant matrix type on the amounts of non-alcohol and methyl rutin derivatives formed during the heating of methanol/water 75/25 $v / v$ extract of Aronia melanocarpa (M.) E. fruits (a1, a2), Sambucus nigra L. fruits (b1, b2), Hypericum perforatum L. herb (c1,

c2), and Tussilago farfara L. leaves (d1, d2) for 1, 2, and $3 \mathrm{~h}$. Numbers under bars correspond to compound numbers reported in Fig. 2. Appropriate concentration axis is indicated by arrows

and for methyl rutin derivatives in the case of $S$. nigra L. fruits (see compounds 3, 4, and 5 in Fig. 3d1 and compounds 7' and 9 ' in Fig. 3b2, respectively).

The latter conclusion suggests that some substances present in the individual plant matrices catalyze or inhibit the rutin transformation process during its extraction.

The ethanolic extract of plant materials containing rutin appears in many pharmaceutical formulations. For this reason, it was decided to compare the rutin transformation process during rutin extraction from the examined plant materials using methanol, ethanol, and their water mixtures containing
$75 \%$ of alcohol. The results of the experiments for a 3-h extraction process are shown in Fig. 4 and lead to the following conclusions:

- Greater amounts of non-alcohol and alcohol rutin derivatives are formed in pure alcohols than in alcohol/water mixture.

- Greater amounts of non-alcohol and alcohol rutin derivatives are formed in methanol and methanol/water mixture than in ethanol and ethanol/water mixture. It is probably connected with greater acidity and reactivity of methanol in relation to ethanol. 



Fig. 4 The influence of plant matrix type on the amounts of non-alcohol, methyl, and ethyl rutin derivatives formed during the heating of methanol, methanol/water 75/25 v/v, ethanol, and ethanol/water 75/25 v/v extract of Aronia melanocarpa (M.) E. fruits (a1, a2), Sambucus nigra L. fruits (b1,

b2), Hypericum perforatum L. herb (c1, c2), and Tussilago farfara L. leaves (d1, d2) for $3 \mathrm{~h}$. Numbers under bars correspond to compound numbers reported in Fig. 2. Appropriate concentration axis is indicated by arrows

- The impact of plant material components on the rutin transformation process is observed in the both alcohols, yet more evidently in methanol and methanol/water mixture.

\section{Conclusions}

As results from Dawidowicz et al. (2016), the heating of methanolic or methanol/water rutin solution under reflux as well as the extraction process of rutin from S. nigra L. flower by methanol and methanol/water mixture causes rutin transformations to its methyl and non-methyl derivatives. The present paper shows that similar transformation processes occur during rutin extraction from other plant materials when methanol, ethanol, and their water mixtures are used as extractants. As results from the obtained data, the degree of rutin transformation in the extraction process depends not only on extraction time and extractant type but also strongly on the plant matrix 
type. The different degree of rutin transformation is probably caused by the plant matrix components in the examined plants. As also suggested in Dawidowicz et al. (2016), two possible processes of rutin transformation and degradation during its extraction should be considered:

- The formation of alcoholic rutin derivatives in the reaction of non-alcoholic rutin derivatives with alcohol. In consequence, the alcoholic rutin derivatives are the final products of the rutin transformation and degradation process;

- The formation of non-alcoholic rutin derivatives from alcoholic rutin derivatives.

As rutin transformation can be a two-step process (see above points considering two-step rutin degradation), the determination of a positive or a negative catalytic role played in this process by different plant matrix components is difficult.

The transformation products of rutin can be mistakenly treated as new components, not naturally present in the examined plant. Alternatively, they can be responsible for the natural plant composition when some or all of them naturally exist in the examined plant, and the transformation process only increases their amounts. This is why our results are especially useful for researchers investigating plant metabolism and looking for new plant components.

\section{Compliance with Ethical Standards}

Conflict of Interest Andrzej L. Dawidowicz declares that he has no conflict of interest. Katarzyna Bernacik declares that she has no conflict of interest. Rafal Typek declares that he has no conflict of interest.

Ethical Approval This article does not contain any studies with human participants or animals performed by any of the authors.

\section{Informed Consent Not applicable.}

Open Access This article is distributed under the terms of the Creative Commons Attribution 4.0 International License (http:// creativecommons.org/licenses/by/4.0/), which permits unrestricted use, distribution, and reproduction in any medium, provided you give appropriate credit to the original author(s) and the source, provide a link to the Creative Commons license, and indicate if changes were made.

\section{References}

Andrade PB, Leitao R, Seabra RM, Oliveira MB, Ferreira MA (1997) Development of an HPLC/diode-array detector method for simultaneous determination of seven hydroxycinnamic acids in green coffee. J Liq Chromatogr Relat Technol 20:2023-2030

Biesaga M (2011) Influence of extraction methods on stability of flavonoids. J Chromatogr A 1218:2505-2512

Bourgaud F, Gravot A, Milesi S, Gontier E (2001) Production of plant secondary metabolites: a historical perspective. Plant Sci 161: $839-851$
Crozier A, Clifford MN, Ashihara H (2006) Plant secondary metabolites: occurrence, structure and role in the human diet. Blackwell Publishing Ltd., Oxford

Dawidowicz AL, Wianowska D (2009) Application of the MSPD technique for the HPLC analysis of rutin in Sambucus nigra L.: the linear correlation of the matrix solid-phase dispersion process. J Chromatogr Sci 47:914-918

Dawidowicz AL, Wianowska D, Gawdzik J, Smolarz DH (2003) Optimization of ASE conditions for the HPLC determination of rutin and isoquercitrin in Sambucus nigra L. J Liq Chromatogr Relat Technol 26:2381-2397

Dawidowicz AL, Bernacik K, Typek R (2016) Rutin transformation during its analysis involving extraction process for sample preparation. Food Anal Methods 9:213-224

Dubber MJ, Sewramb V, Mshicilelib N, Shephardb GS, Kanfer I (2005) The simultaneous determination of selected flavonol glycosides and aglycones in Ginkgo biloba oral dosage forms by high-performance liquid chromatography-electrospray ionisation-mass spectrometry. J Pharm Biomed Anal 37:723-731

Guardia T, Rotelli AE, Juarez AO, Pelzer LE (2001) Anti-inflammatory properties of plant flavonoids. Effects of rutin, quercetin and hesperidin on adjuvant arthritis in rat. II Farmaco 56:683-687

Kennedy DO, Wightman EL (2011) Herbal extracts and phytochemicals: plant secondary metabolites and the enhancement of human brain function. Adv Nutr 2:32-50

Mohd Zainol MK, Abdul-Hamid A, Abu Bakar F, Pak Dek S (2009) Effect of different drying methods on the degradation of selected flavonoids in Centella asiatica. Int Food Res J 16:531-537

Navarro-Núñez L, Lozano ML, Palomo M, Martínez C, Vicente V, Castillo J, Benavente-García O, Diaz-Ricart M, Escolar G, Rivera $\mathrm{J}$ (2008) Apigenin inhibits platelet adhesion and thrombus formation and synergizes with aspirin in the suppression of the arachidonic acid pathway. J Agric Food Chem 56:2970-2976

Pandey KB, Rizvi SI (2009) Plant polyphenols as dietary antioxidants in human health and disease. Oxidative Med Cell Longev 2:270-278

Rohn S, Buchner N, Driemel G, Rauser M, Kroh LW (2007) Thermal degradation of onion quercetin glucosides under roasting conditions. J Agric Food Chem 55:1568-1573

Suárez-Quiroz ML, Campos AA, Alfaro GV, González-Ríos O, Villeneuve P, Figueroa-Espinoza MC (2014) Isolation of green coffee chlorogenic acids using activated carbon. J Food Compos Anal 33:55-58

Uppugundla N, Engelberth A, Ravindranath SV, Clausen EC, Lay JO, Gidden J, Carrier DJ (2009) Switchgrass water extracts: extraction, separation and biological activity of rutin and quercitrin. J Agric Food Chem 57:7763-7770

Wang J, Zhao LL, Sun GX, Liang Y, Wu FA, Chen Z, Cui SM (2011) A comparison of acidic and enzymatic hydrolysis of rutin. Afr $\mathrm{J}$ Biotechnol 10:1460-1466

Wianowska D, Typek R, Dawidowicz AL (2015) How to eliminate the formation of chlorogenic acids artefacts during plants analysis? Sea sand disruption method (SSDM) in the HPLC analysis of chlorogenic acids and their native derivatives in plants. Phytochemistry 117:489-499

Yang J, Guo J, Yuan J (2008) In vitro antioxidant properties of rutin. LWT-Food Sci Technol 41:1060-1066

You HJ, Ahn HJ, Ji GE (2010) Transformation of rutin to antiproliferative quercetin-3-glucoside by Aspergillus niger. J Agric Food Chem 58: 10886-10892

Zenkevich IG, Eshchenko AY, Makarova SV, Vitenberg AG, Dobryakov YG, Utsal VA (2007) Identification of the products of oxidation of quercetin by air oxygen at ambient temperature. Molecules 12:654-672

Zvezdanović JB, Stanojević JS, Markocić DZ, Cvetković DJ (2012) Irreversible UV-induced quercetin and rutin degradation in solution studied by UV spectrophotometry and HPLC chromatography. J Serb Chem Soc 77:297-312 